\section{Evaluation of Three Commercial Biopesticides for the Reduction of Diaphorina citri (Hemiptera: Liviidae) Populations}

\author{
Augusto Ramírez-Godoy, María del Pilar Vera-Hoyos, \\ Natalia Jiménez-Beltrán, and Hermann Restrepo-Díaz ${ }^{1}$ \\ Departamento de Agronomía, Facultad de Ciencias Agrarias, Universidad \\ Nacional de Colombia, Bogotá, Colombia
}

Additional index words. botanical pesticides, entomopathogenic fungus, imidacloprid, integrated pest management

\begin{abstract}
Asian citrus psyllid (ACP), Diaphorina citri Kuwayama, is the most serious threat to the global citrus industry, and its management has mainly depended on the application of chemical insecticides. The use of biopesticides can play an important role in regulating this pest. In a first test, two separate experiments were conducted in two different municipalities (Apulo and Jerusalen, Cundinamarca, Colombia) to evaluate the effect of foliar Beauveria bassiana and imidacloprid sprays on ACP populations in 2015 and 2016, respectively. In a second test, two separate tests were carried out in commercial Tahiti lime orchards to evaluate the efficacy of three different commercial biopesticides (Beauveria bassiana and extracts of Sophora sp. and garlic-chili pepper). In test 1 , imidacloprid-treated trees showed a reduction $(60 \%$ and $80 \%)$ in cumulative ACP adults in 2016. ACP cumulative nymphs were also diminished by foliar imidacloprid and $B$. bassiana application, between $40 \%$ and $65 \%$ in 2015 and 2016 , respectively. ACP cumulative eggs showed lower individuals in imidacloprid-treated flushes at 3 and 4 weeks after treatment 9 (WAT) in 2016. In test 2, the results obtained showed ACP adults and eggs unaffected by biopesticide treatments; nymphs were reduced $50 \%$ to $75 \%$ in trees treated with the three biopesticides in comparison with control trees. All three biopesticides tested can be considered useful tools in integrated pest management (IPM) programs for ACP, since these products reduced immature ACP individuals between $50 \%$ and $75 \%$ under field conditions.
\end{abstract}

Asian citrus psyllid (ACP), Diaphorina citri Kuwayama (Hemiptera: Liviidae), is currently the most important insect pest in the global citrus industry because it is the vector responsible for transmission of the bacteria Candidatus Liberibacter asiaticus and Candidatus Liberibacter americanus, the putative causative agents of Huanglongbing disease (HLB) (Halbert et al., 2000). ACP was officially reported in Colombia in 2007 (Santivañez et al., 2013). Recently, the Colombian Agricultural Institute (ICA) declared a state of phytosanitary emergency in 2015 due to the presence of ACP adults carrying the bacteria that causes HLB (ICA, 2015). In Colombia, citrus crops occupy an area of 75,000 ha, with production of 1.75 million tons per year. Acid limes are one of the most cultivated species, with production of 360,836 tons in 2014 (Agronet, 2017).

The frequent application of insecticides has been an important tool used by growers to control ACP populations (Chen and Stelinski,

Received for publication 28 June 2018. Accepted for publication 15 Aug. 2018.

${ }^{1}$ Corresponding author. E-mail: hrestrepod@unal. edu.co.
2017; Tiwari et al., 2011). Repeated application of insecticides, however, has caused strong selection pressure, resulting in resistance and reducing the effectiveness of insecticides (Boina and Bloomquist, 2015). Likewise, the excessive use of insecticides may be economically unfeasible for growers and may also affect natural enemies that contribute to the control of ACP (LezamaGutiérrez et al., 2012). For this reason, biopesticides have been considered as substitutes or in rotation with current synthetic insecticides in integrated pest management (IPM) programs for ACP (Khan et al., 2015; Santos et al., 2015; Weathersbee and McKenzie, 2005).

Entomopathogenic fungi have shown promising results as eco-friendly biopesticides in the control of the ACP populations because they manage to infect the insect in all stages of its development (GandarillaPacheco et al., 2013; Kumar et al., 2017; Saldarriaga-Ausique et al., 2017). Additionally, these biocontrol agents are commercially available and represent an effective control alternative, since they help to reduce the problem of insecticide resistance and negative effects on populations of natural enemies (Saldarriaga-Ausique et al., 2017). Some strains of the entomopathogenic fungus
Beauveria bassiana (Bals.-Criv.) (Hypocreales: Clavicipitaceae) have been reported to be a potential regulator of ACP populations. Several studies under controlled conditions have shown high efficacy against the immature stages (nymphs) of this insect (Ferreira Pinto et al., 2012; Ibarra-Cortés et al., 2017). However, efficacy tests under field conditions are still scarce (OrduñoCruz et al., 2015; Saldarriaga-Ausique et al., 2017).

Insecticides obtained from natural sources such as plant extracts can have pesticidal effects on arthropods and have been used in IPM programs because they help to reduce environmental pollution, conserve natural enemies of pests, and ward off pest resurgence (Khan et al., 2014, 2015). Phytochemicals extracted from the leaves, stems or roots of Sophora sp. (L.) (Fabales: Fabaceae) or Azadirachta indica (A. Juss) (Sapindales: Meliaceae), such as matrine or azadirachtin, have pesticide activity (Xin et al., 2016). Recently, matrine extracts have been studied alone or combined with other chemicals to control different pests, such as Coptotermes formosanus (Shiraki) (Mao and Henderson, 2007), Bemisia tabaci (Gennadius) (Ali et al., 2017), Mythimna separata (Walker), and Plutella xylostella (Linnaeus) (Huang et al., 2017). Additionally, the use of matrine-based biopesticides has also become important in controlling ACP as an IPM tool in recent years (Fang et al., 2018; Zanardi et al., 2015).

Allium sativum (L.) extracts have shown positive effects in controlling insect pests in commercial crops (Zehnder et al., 2007). ACP adults showed $85 \%$ repellence when citrus trees were treated with foliar garlic extract sprays at a concentration of $50 \mathrm{ppm}$ (Cazares-Alonso et al., 2014). Bioassays developed by Mann et al. (2011) also showed higher repellency of adults in response to exposure to sulfur volatiles obtained from garlic bulbs. The application of Capsicum annuum (L.) extracts has also shown positive results in the management of insect pests because they contain capsaicin, which has lethal and antifeeding effects on invertebrates (Baidoo and Mochiah, 2016; Kazem and El-Shereif, 2010).

Although ACP was reported in Colombia about a decade ago, control of this pest with biopesticides is still scarce (Mejía-Vásquez, 2016). Additionally, most information available on the effectiveness of biopesticides on $\mathrm{ACP}$ has been found mainly through research carried out under laboratory or greenhouse conditions. The effectiveness of these biopesticides under field conditions has been poorly documented, especially in tropical dry forest conditions, and ACP mainly develops in these habitats in Colombia (Ebratt-Ravelo et al., 2011). For this reason, the objectives of this study were to evaluate the reduction of ACP populations (adults, nymphs, and eggs) through the application of three different commercial biopesticides [B. bassiana, extracts of Sophora sp., and a mixture of extracts of Allium sativum (L.) and Capsicum annuum (L.)] under field conditions. 


\section{Materials and Methods}

Test 1: Evaluation of a commercial biopesticide vs. a synthesis insecticide on $A C P$ population control. In this test, the objective was to evaluate the efficacy of a commercial biopesticide (B. bassiana) vs. a synthetic insecticide on ACP control. Two separate short-term evaluations (five weeks) were conducted in two commercial orchards of Tahiti lime located on two different farms in the Department of Cundinamarca in Colombia. The first evaluation was carried out on a farm with a drip irrigation system located in the municipality of Jerusalén (lat. $4^{\circ} 33^{\prime} 33.91^{\prime \prime} \mathrm{N}$, long. $74^{\circ} 41^{\prime} 39.09^{\prime \prime} \mathrm{W}$, altitude: elevation $316 \mathrm{~m}$ ) from Oct. to Nov. 2015. The second evaluation was also performed on a farm with drip irrigation located in the municipality of Apulo (lat. $4^{\circ} 30^{\prime} 44.73$ "N, long. $74^{\circ} 34^{\prime} 57.58^{\prime \prime} \mathrm{W}$, altitude: elevation $420 \mathrm{~m}$ ) from Oct. to Nov. 2016. The climatic conditions (rainfall and average temperature) during two experiments in both locations are presented in Fig. 1. The two evaluations were carried out on 6- and 8year-old 'Tahiti lime' (Citrus latifolia Tanaka) grafted onto 'Citrumelo CPB 4475' (Poncirus trifoliata L. $\times$ Citrus paradise
Macfad) trees in both locations, respectively. Additionally, all trees were spaced $8 \times 5 \mathrm{~m}$.

The treatments studied were 1) control, no foliar treatment; 2) trees treated with imidacloprid (Confidor ${ }^{\circledR} 350$ SC; Bayer, Bogotá, Colombia) at $0.10 \mathrm{~L}$ a.i. per ha; and 3) trees treated with a commercial strain of $B$. bassiana (spores of the GHA strain) (Mycotrol ${ }^{\circledR}$; Laverlam S.A., Cali, Colombia). A conidial germination viability of $90 \%$ for $B$. bassiana was obtained using the method described by Oliveira et al. (2015).

Foliar imidacloprid and $B$. bassiana sprays were applied early morning at 0 weeks after treatment (WAT). In both treatments, spray applications (2 L per tree) were performed with a pesticide backpack sprayer (Royal Condor; Soacha, Colombia), wetting the upper and lower surfaces until dripping. Treatments were arranged in randomized complete block design (four blocks). For each experimental unit (treatment), three trees were used per treatment, for a total of 12 trees per treatment. In all treatments, guard trees were used to avoid edge effects due to drift by foliar sprays.

Test 2: Evaluation of three commercial biopesticides on ACP population control. Taking into account the previous observations in test 1 , the aim of these experiments was to compare the use of $B$. bassiana vs. plant extract biopesticides (Sophora sp. and a mixture of extracts of A. sativum and C. annuum). Two separate experiments were carried out between Aug.and Sept. 2017 at the farms ' $\mathrm{La}$ Rochela' (lat. $4^{\circ} 33^{\prime} 22.1^{\prime \prime} \mathrm{N}$, long. $74^{\circ} 43^{\prime} 36.8$ "W, altitude: elevation $305 \mathrm{~m}$ ) and 'Rochelita' (lat. $4^{\circ} 33^{\prime} 07.6^{\prime \prime} \mathrm{N}$, long. $74^{\circ} 44^{\prime} 45.6^{\prime \prime} \mathrm{W}$, altitude: elevation $263 \mathrm{~m}$ ) located in the municipality of Jerusalén in the Department of Cundinamarca in Colombia. The climatic conditions (precipitation and maximum and minimum temperatures) during the experiments at both farms are summarized in Fig. 2. The two experiments were conducted on 2- and 5-year-old 'Tahiti lime' (C. latifolia Tanaka) grafted onto 'Citrumelo CPB 4475' $(P$. trifoliata $\mathrm{L} . \times C$. paradisi Macfad) trees at the two farms under drip irrigation, respectively. All trees were spaced $8 \times 5 \mathrm{~m}$.

The treatments established in both farms were 1) trees without foliar biopesticide sprays (control); 2) trees treated with foliar $B$. bassiana (spores of the GHA strain) applications (Mycotrol ${ }^{\circledR}$; Laverlam S.A.) at a commercial dose of $1 \times 10^{9}$ spores $\cdot \mathrm{L} \mathrm{H}_{2} \mathrm{O}$; 3 ) trees treated with foliar Sophora spp. extract (with a content of $0.03 \%$ matrine)

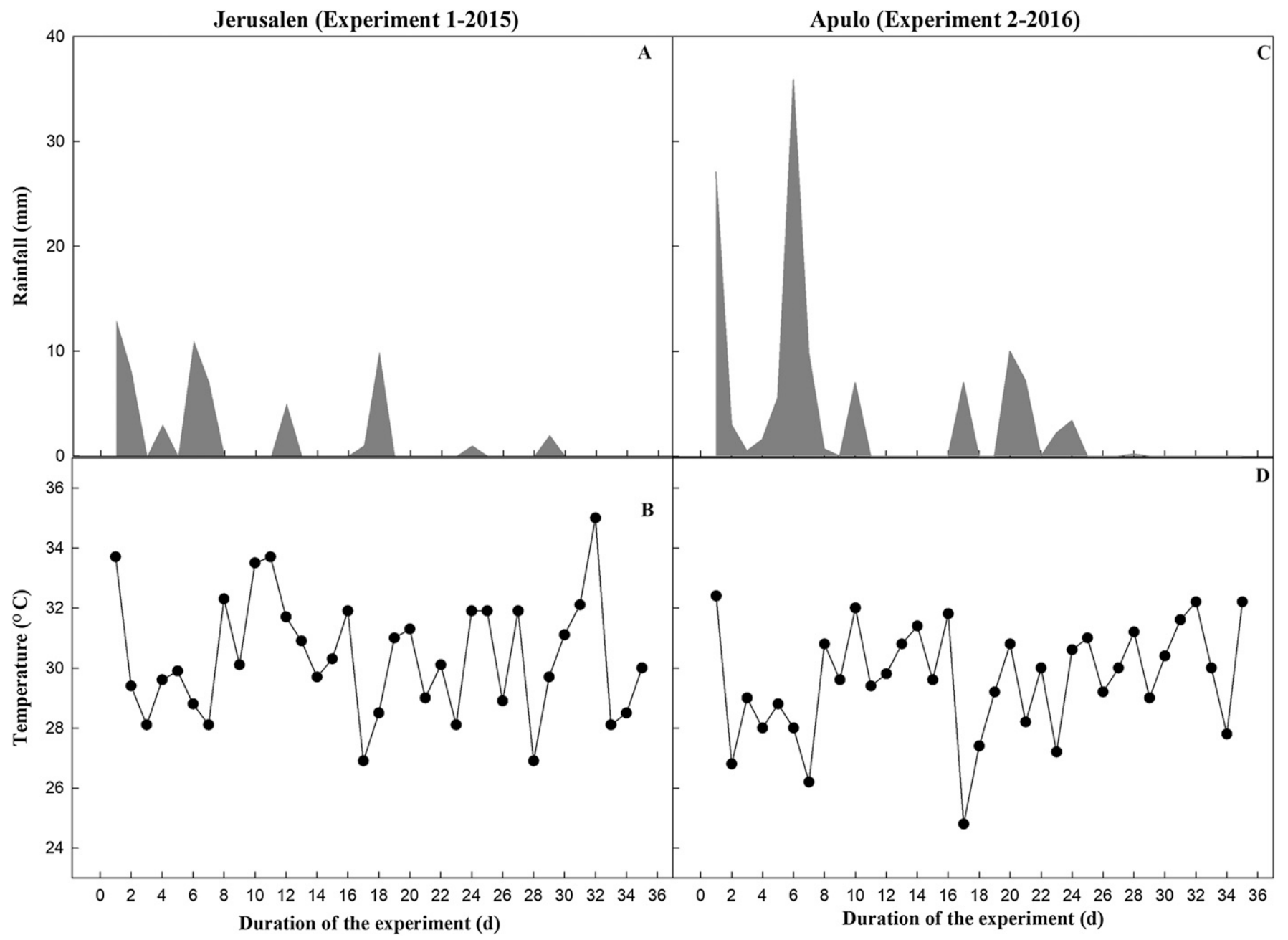

Fig. 1. Rainfall records and average temperatures in the municipalities of Jerusalén (2015) (A and B) and Apulo (2016) (C and D), respectively. 


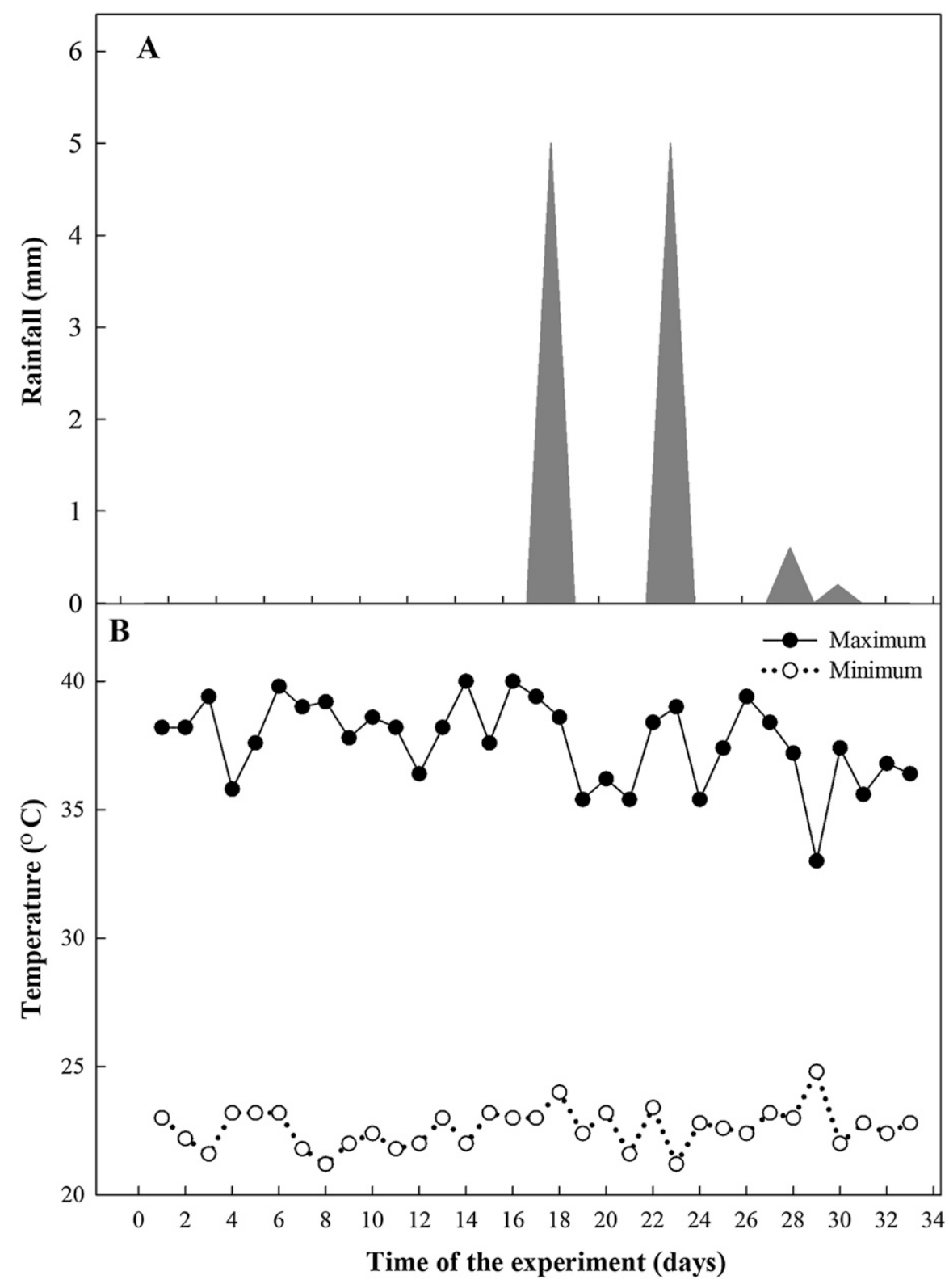

Fig. 2. Rainfall records (A) and average temperature (B) for the evaluation trials of the effects of three biopesticides on the control of ACP populations in the municipality of Jerusalén. Data were obtained from a nearby weather station [Jerusalén station (lat. $4^{\circ} 56^{\prime} 18.06^{\prime \prime} \mathrm{N}$, long. $74^{\circ} 70^{\prime} 23.99^{\prime \prime} \mathrm{W}$, altitude: elevation $297 \mathrm{~m}$ ) of the Institute of Hydrology, Meteorology and Environmental Studies (IDEAM)].

(ADNGREEN ${ }^{\circledR}$; A.D.N Adelante SAS, Rionegro, Colombia) at a commercial dose of $3.2 \mathrm{~mL} \cdot \mathrm{L}^{-1} \mathrm{H}_{2} \mathrm{O}$; and 4) trees treated with foliar garlic-chili pepper applications (with a concentration of $54.2 \%$ garlic $+43.4 \%$ chili pepper extract) (Capsialil SL ${ }^{\circledR}$; Ecoflora Agro, Medellin, Colombia) at a commercial dose of $2.8 \mathrm{~mL} \cdot \mathrm{L}^{-1} \mathrm{H}_{2} \mathrm{O}$. A conidial germination viability of $93 \%$ for $B$. bassiana was obtained using the method described by Oliveira et al. (2015).

Foliar biopesticide applications at both farms were carried out at 0 and 2 WAT) between 7:00 and 9:00 AM using a back pump with an application volume of $2 \mathrm{~L} \mathrm{H}_{2} \mathrm{O}$ per tree, wetting both the upper and lower leaf surfaces. Foliar applications were performed without any adjuvants. For each treatment, three trees were also used in each experiment.
Treatments were arranged in a randomized complete block design (four blocks). In all treatments, guard trees were also used to avoid edge effects due to drift by foliar sprays.

Population dynamics of ACP individuals. The method described by Sétamou et al. (2008) was used to estimate ACP population variability in both tests. Relative infestation levels of ACP adults, eggs, and nymphs were estimated separately by randomly reviewing five young flush shoots $(0.5-1.0$ $\mathrm{cm})$ per tree at each of the four cardinal points. In addition, eggs and nymphs were counted in situ and registered per flush shoot using a 15X handheld lens. In general, samples for both trials were collected between zero and four WAT at intervals of seven days per sampling.
Efficacy percentage. The method described by Henderson and Tilton (1955) was used to assess treatment efficacy on ACP populations at the end of the experiments ( 4 WAT) in both tests. ACP population (adults, nymphs, and eggs) levels recorded separately before and after treatments were used to calculate efficacy percentage. In general, the efficacy percentage for each treatment was determined using the following formula:

$$
\% \text { Efficacy }=100 x\left(1-\frac{(\operatorname{Ta} \times C b)}{(\operatorname{Tb} \times C a)}\right)
$$

where $T$ is the treated population, $C$ is the control population, $a$ is the sampled population after treatment, and $b$ is the sampled population before treatment.

Experimental design and statistical analysis. A randomized block design was used to study the effects of foliar B. bassiana and imidacloprid treatments on ACP populations in test 1. A multiobservational $F$-protected analysis (a series of experiments) was used for test 2 . To analyze ACP populations, data were transformed $(\log X+1)$, since data were not normally distributed. Percentage data were transformed using the arcsine formula. When differences were observed $(P \leq 0.05)$ in an ANOVA, the Tukey post hoc test was used to compare means. The data were analyzed using the statistical program Statistix (Version 9, Tallahassee, FL).

\section{Results and Discussion}

Test 1: Cumulative individuals and efficacy percentage of a commercial biopesticide vs. a synthesis insecticide. Significant differences were observed in the number of ACP eggs, nymphs, and adults in Tahiti lime trees due to treatments in the two different experiments (Fig. 3). Foliar treatment applications affected cumulative adults in both experiments. Imidacloprid-treated trees showed a reduction (between $60 \%$ and $80 \%$ ) on cumulative ACP adults, obtaining differences among treatments mainly at 1 $(\mathrm{F}=3.09 ; \mathrm{df}=2,35 ; P=0.040)$ and $2(\mathrm{~F}=$ 3.48 ; $\mathrm{df}=2,35 ; P=0.043) \mathrm{WAT}$ in 2015 , and $3(\mathrm{~F}=4.36 ; \mathrm{df}=2,47 ; P=0.019)$ and $4(\mathrm{~F}=$ $6.10 ; \mathrm{df}=2,47 ; P=0.004)$ WAT in 2016 (Fig. 3A and B). Regarding ACP cumulative nymphs, foliar imidacloprid application also caused a reduction in this developmental stage. In 2015, differences $(\mathrm{F}=2.15$; $\mathrm{df}=$ $2,35 ; P=0.05)$ were only recorded at $4 \mathrm{WAT}$, where imidacloprid-treated flush shoots had 4.2 individuals compared with 8.5 individuals in untreated flushes (Fig. 3C) and cumulative nymphs were affected by treatments starting at $2(\mathrm{~F}=2.41 ; \mathrm{df}=2,47 ; P=0.049)$ WAT in 2016 (Fig. 3D). Control trees showed higher individual numbers $(10 \mathrm{cu}-$ mulative individuals per flush shoot) in comparison with $B$. bassiana and imidacloprid treatments (4 cumulative individuals). In relation to cumulative eggs, differences were not observed in 2015 (Fig. 3E). However, differences were recorded in 2016, when imidacloprid-treated flushes showed lower cumulative individuals at $3(\mathrm{~F}=3.31$; 


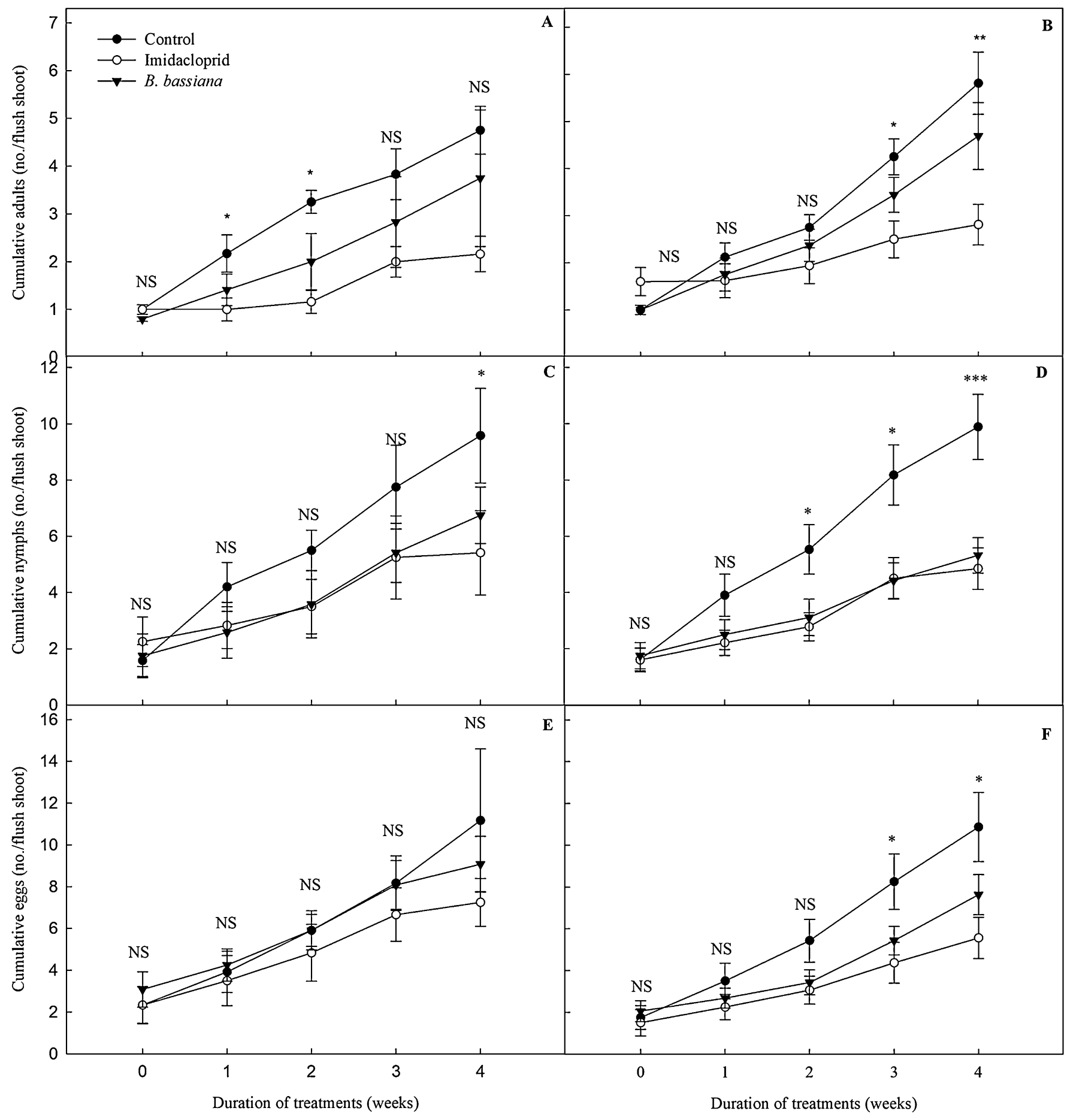

Fig. 3. Average cumulative ACP individuals (adults, nymphs, and eggs) per flush shoot in Tahiti lime trees treated with imidacloprid and Beauveria bassiana in

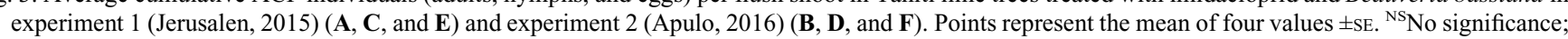
***significant difference $(P \leq 0.001)$; **significant difference $(P \leq 0.01)$; *significant difference $(P \leq 0.05)$ compared with the control according to the Tukey test. Foliar treatment sprays were carried out at 0 weeks after treatments.

$\mathrm{df}=2,47 ; P=0.046)$ and $4(\mathrm{~F}=3.82 ; \mathrm{df}=$ $2,47 ; P=0.03)$ WAT (Fig. 3F).

The percent efficacy of treatments (B. bassiana and imidacloprid) was evaluated on ACP adults, nymphs, and eggs at 2 and 4 WAT in both experiments (2015 and 2016) (Fig. 4). In general, differences were not found on the percent efficacy in all developmental stages (adults, nymphs, and eggs) between imidacloprid and B. bassiana at 2 WAT in both years. However, flush shoots treated with imidacloprid showed a percent efficacy of $58 \%$ and $62 \%$ on adult population compared with $33 \%$ and $35 \%$ in trees treated with B. bassiana in 2015 and 2016 at 4 WAT, respectively (Fig. 4A and B). Imidacloprid-treated flushes also showed a higher efficacy percentage (72\%) on nymph control than $B$. bassiana (43\%) in 2015 (Fig. 4C). Nevertheless, opposite results were observed for this variable in 2016 , in which $B$. bassiana showed a better efficacy $(62 \%)$ in comparison with imidacloprid (40\%) (Fig. 4D). Differences were not obtained in percentage efficacy $(45 \%)$ on ACP eggs among treatments in both years (Fig. 4F). 


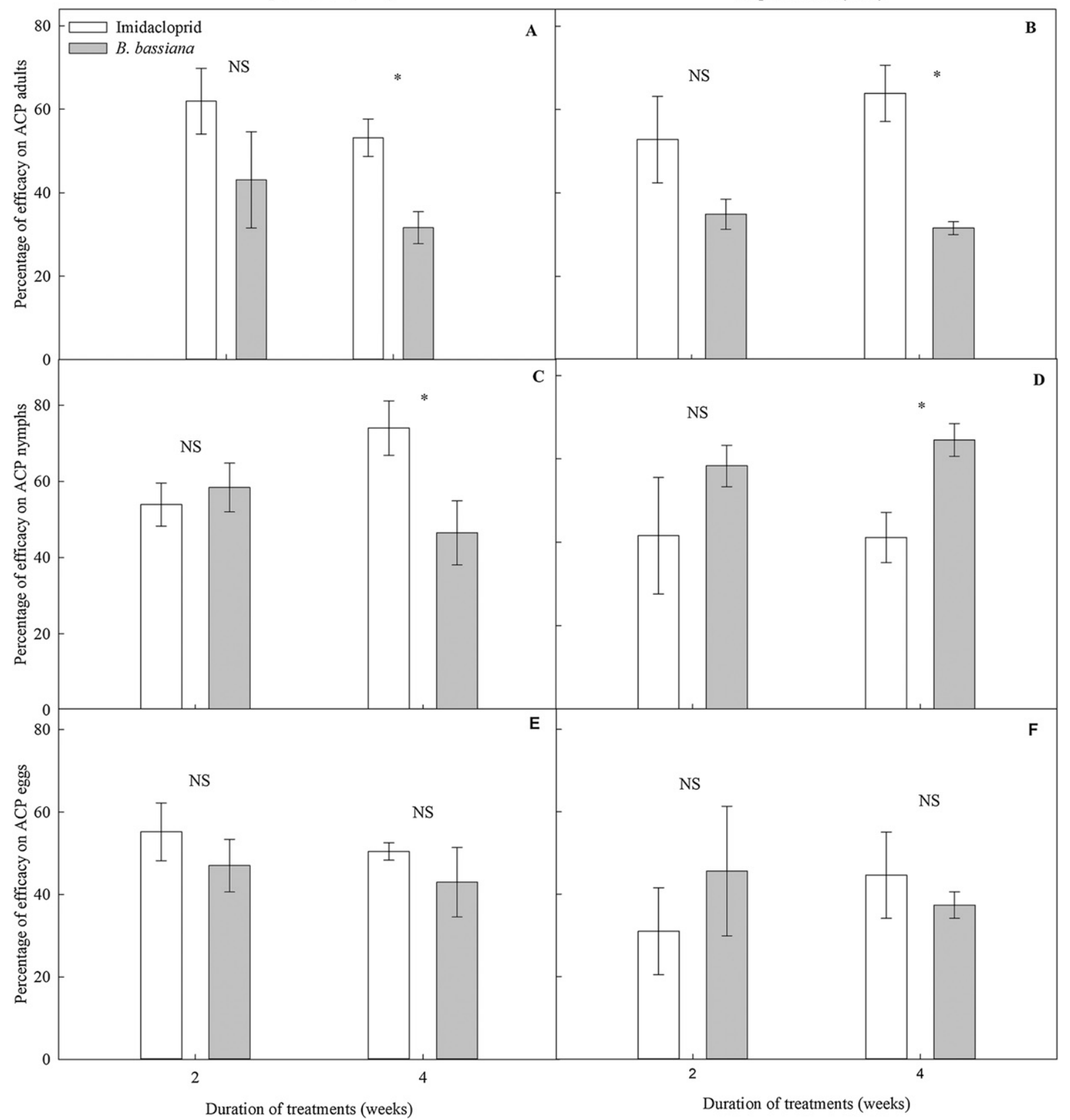

Fig. 4. Summary of the efficiency percentage per flush shoot in Tahiti lime trees treated with imidacloprid and Beauveria bassiana in experiment 1 (Jerusalen, 2015) [adults (A), nymphs (C), and eggs (E)] and experiment 2 (Apulo, 2016) [adults (B), nymphs (D), and eggs (F)]. Bar charts represent the mean of four values \pm SE. ${ }^{N S}$ No significance; *significant difference $(P \leq 0.05)$ according to the Tukey test. Foliar treatment sprays were carried out at 0 weeks after treatments.

Test 2: Cumulative individuals and efficacy percentage of three commercial biopesticides. ACP adults were unaffected by the use of the three different commercial biopesticides in this test (Table 1; Fig. 5A). However, the nymph population was reduced by the use of $B$. bassiana and commercial extracts of Sophora spp. and garlic-chili pepper, with differences $(\mathrm{F}=3.23$; df $=$ 3,$95 ; P=0.026$ ) obtained in comparison with untreated trees from 1 WAT. Tahiti lime trees treated with foliar biopesticide sprays presented $\approx 50 \%$ to $75 \%$ fewer nymphs compared with control trees at 1 (1.33 vs. 2.42 nymphs per flush shoot), 2 ( 0.43 vs. 1.33 nymphs per flush shoot), 3 (0.40 vs. 1.67
Table 1. Probability of F statistic ( $P>\mathrm{F})$ of ACP individuals per flush shoot (adults, nymphs, and eggs) on Tahiti lime trees treated with three commercial biopesticides.

\begin{tabular}{|c|c|c|c|c|c|}
\hline & \multicolumn{5}{|c|}{ Weeks after treatments (WAT) } \\
\hline & $0^{\mathrm{z}}$ & 1 & 2 & 3 & 4 \\
\hline Farms (F) & $P=0.739$ & $P=0.079$ & $\begin{array}{c}\text { Adults } \\
P=1.00\end{array}$ & $P=0.513$ & $P=0.565$ \\
\hline Treatments $(\mathrm{T})$ & $P=0.924$ & $P=0.285$ & $P=0.119$ & $P=0.281$ & $P=0.801$ \\
\hline $\mathrm{F} \times \mathrm{T}$ & $P=0.517$ & $P=0.062$ & $\begin{array}{c}P=1.00 \\
\text { Nymphs }\end{array}$ & $P=0.933$ & $P=0.306$ \\
\hline Farms (F) & $P=0.336$ & $P=0.008$ & $P=0.751$ & $P=0.003$ & $P=0.074$ \\
\hline Treatments $(\mathrm{T})$ & $P=0.135$ & $P=0.026$ & $P=0.002$ & $P=0.000$ & $P=0.000$ \\
\hline $\mathrm{F} \times \mathrm{T}$ & $P=0.396$ & $P=0.018$ & $\begin{array}{c}P=0.991 \\
\text { Eggs }\end{array}$ & $P=0.452$ & $P=0.191$ \\
\hline Farms (F) & $P=0.000$ & $P=0.001$ & $P=0.592$ & $P=0.045$ & $P=0.373$ \\
\hline Treatments $(\mathrm{T})$ & $P=0.051$ & $P=0.101$ & $P=0.001$ & $P=0.183$ & $P=0.000$ \\
\hline $\mathrm{F} \times \mathrm{T}$ & $P=0.089$ & $P=0.896$ & $P=0.774$ & $P=0.652$ & $P=0.902$ \\
\hline
\end{tabular}

${ }^{\mathrm{z}}$ Foliar applications of biopesticides were conducted at 0 and 2 weeks after initiating the treatments. 
nymphs per flush shoot) and 4 ( 0.35 vs. 1.45 nymphs per flush shoot) WAT (Fig. 5B). Regarding egg population dynamics in flush shoots, differences were only observed at 2 $(\mathrm{F}=5.49 ; \mathrm{df}=3,95 ; P=0.001)$ and $4(\mathrm{~F}=$ $11.31 ; \mathrm{df}=3,95 ; P=0.000)$ WAT. The three commercial biopesticides caused a reduction of $54 \%$ and $62 \%$ compared with untreated trees at 2 and 4 WAT, respectively (Fig. 5C).

The analysis of the population dynamics expressed as individuals that had accumulated throughout the test showed that the use of biopesticides had no effect on adults, but it did affect the immature stages (nymphs and eggs) (Table 2; Fig. 6). Differences were observed for nymphs and eggs at $1(\mathrm{~F}=$ 3.53 ; $\mathrm{df}=3,95 ; P=0.018)$ and $2(\mathrm{~F}=3.63$; $\mathrm{df}=3,95 ; P=0.016)$ WAT, respectively. In general, the three biopesticides caused an average decrease of $60 \%$ and $40 \%$ in nymph and egg cumulative individuals at the end of the experiment (4 WAT), respectively.

In test 2, the percent efficacy of the treatments (B. bassiana and commercial extracts of Sophora spp. and garlic-chili pepper) was also evaluated at 2 and 4 WAT. Foliar biopesticides sprays were equally effective on suppressing ACP adults, nymphs, and eggs, showing a percent efficacy of around $40 \%$ in the management of ACP individuals (adults, nymphs, and eggs) for all treatments (Fig. 7).

The use of $B$. bassiana showed its potential as a biological control agent of $D$. citri, with a nymph control percentage between $50 \%$ and $60 \%$ in both tests. Several authors have reported similar results under laboratory conditions (Ferreira Pinto et al., 2012; Lezama-Gutiérrez et al., 2012). Padulla and Alves (2009) found a control percentage of $\approx 80 \%$ after $7 \mathrm{~d}$ of exposure under laboratory conditions. Saldarriaga-Ausique et al. (2017) estimated mortality levels of $\approx 50 \%$ under commercial conditions in the dry season of the year due to the influence of temperature and relative humidity. Padulla and Alves (2009) and Ferreira Pinto et al. (2012) reported that the mycotoxin oosporin is related to nymph mortality, affecting mainly thirdinstar nymphs. Our results did not show any differences on ACP adult control. Saldarriaga-Ausique et al. (2017) found $80 \%$ mortality of adults, and reported that the high mortality rate is mainly related to environmental (rainfall, temperature, ultraviolet radiation) and technical (application number, rate) conditions. A plausible explanation for the lack of ACP adult control by foliar $B$. bassiana sprays could be that weather conditions (low rainfall and high daytime temperatures) during trials may have conditioned proper ACP colonization by oospores (Figs. 1 and 2).

Use of botanical insecticides could reduce ACP populations, insecticide resistance, and/ or negative impact on ACP natural predators (Khan et al., 2014). The application of commercial extracts of Sophora spp. and garlic-chili pepper also had noteworthy effects in keeping the populations of immature ACP low (Table 1). Previous studies by

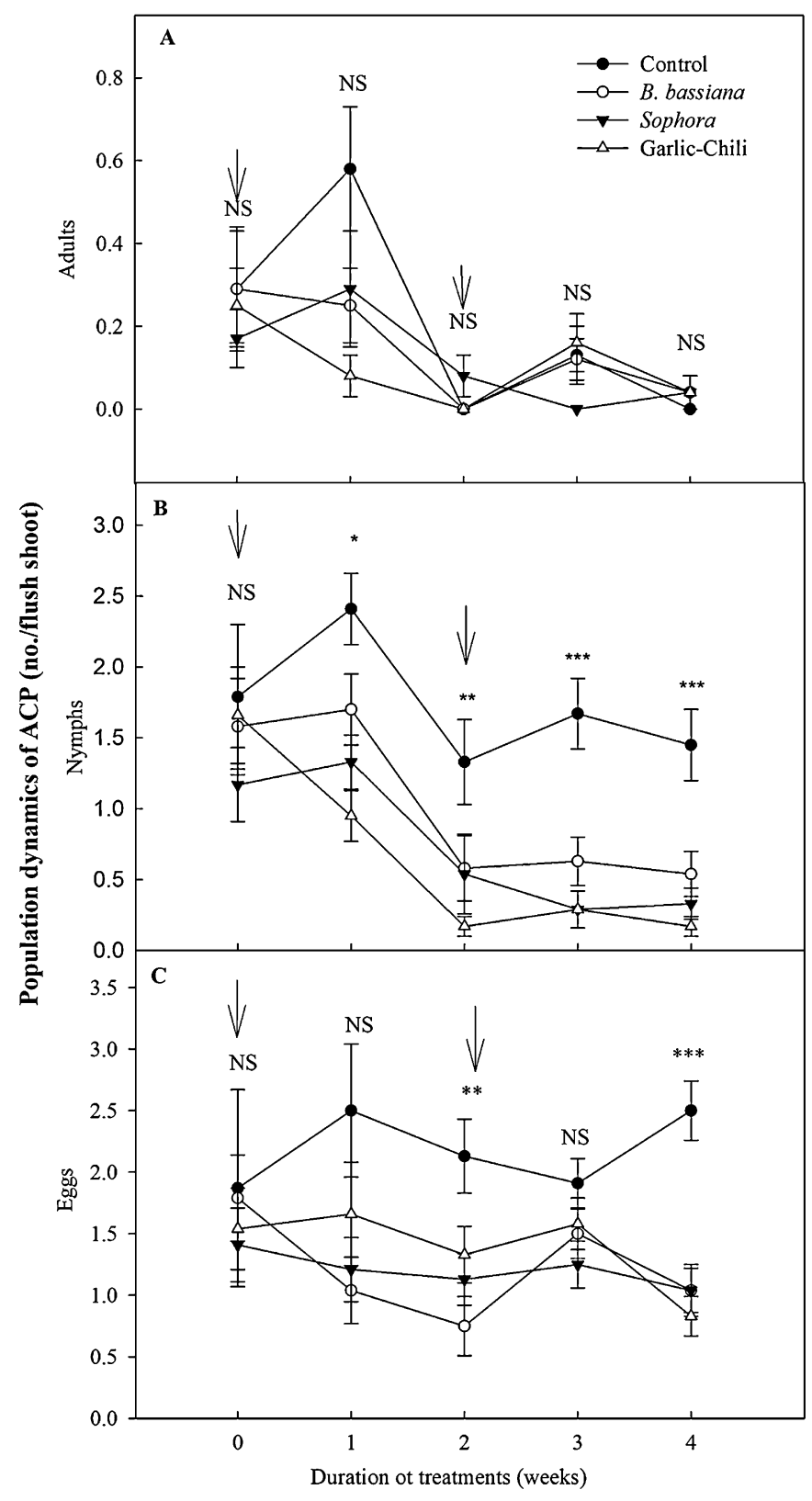

Fig. 5. Mean of ACP adults (A), nymphs (B), and eggs (C) per flush shoot in Tahiti lime trees treated with three commercial biopesticides (Sophora spp., garlic-chili pepper concentrated emulsion, or $B$. bassiana). Points represent the mean of four values \pm SE. NS No significance; $* * *$ significant difference $(P \leq 0.001) ; * *$ significant difference $(P \leq 0.01)$; *significant difference $(P \leq 0.05)$ compared with the control according to the Tukey test. Arrows indicate foliar commercial biopesticide applications.

Table 2. Probability of F statistic $(P>F)$ of cumulative ACP individuals (adults, nymphs, and eggs) on Tahiti lime trees treated with three commercial biopesticides.

\begin{tabular}{|c|c|c|c|c|c|}
\hline & \multicolumn{5}{|c|}{ Weeks after treatments (WAT) } \\
\hline & $0^{\mathrm{z}}$ & 1 & 2 & 3 & 4 \\
\hline Farms (F) & $P=0.739$ & $P=0.254$ & $\begin{array}{c}\text { Adults } \\
P=0.302\end{array}$ & $P=0.164$ & $P=0.210$ \\
\hline Treatments $(\mathrm{T})$ & $P=0.924$ & $P=0.558$ & $P=0.635$ & $P=0.616$ & $P=0.717$ \\
\hline $\mathrm{F} \times \mathrm{T}$ & $P=0.517$ & $P=0.072$ & $\begin{array}{c}P=0.562 \\
\text { Nymphs }\end{array}$ & $P=0.413$ & $P=0.217$ \\
\hline Farms (F) & $P=0.336$ & $P=0.212$ & $P=0.692$ & $P=0.327$ & $P=0.217$ \\
\hline Treatments $(\mathrm{T})$ & $P=0.135$ & $P=0.018$ & $P=0.000$ & $P=0.000$ & $P=0.000$ \\
\hline $\mathrm{F} \times \mathrm{T}$ & $P=0.396$ & $P=0.203$ & $\begin{array}{c}P=0.262 \\
\text { Eggs }\end{array}$ & $P=0.409$ & $P=0.311$ \\
\hline Farms (F) & $P=0.003$ & $P=0.000$ & $P=0.000$ & $P=0.000$ & $P=0.000$ \\
\hline Treatments $(\mathrm{T})$ & $P=0.051$ & $P=0.242$ & $P=0.016$ & $P=0.006$ & $P=0.000$ \\
\hline $\mathrm{F} \times \mathrm{T}$ & $P=0.089$ & $P=0.177$ & $P=0.464$ & $P=0.339$ & $P=0.180$ \\
\hline
\end{tabular}

${ }^{\mathrm{z}}$ Foliar applications of biopesticides were conducted at 0 and 2 weeks after initiating the treatments. 


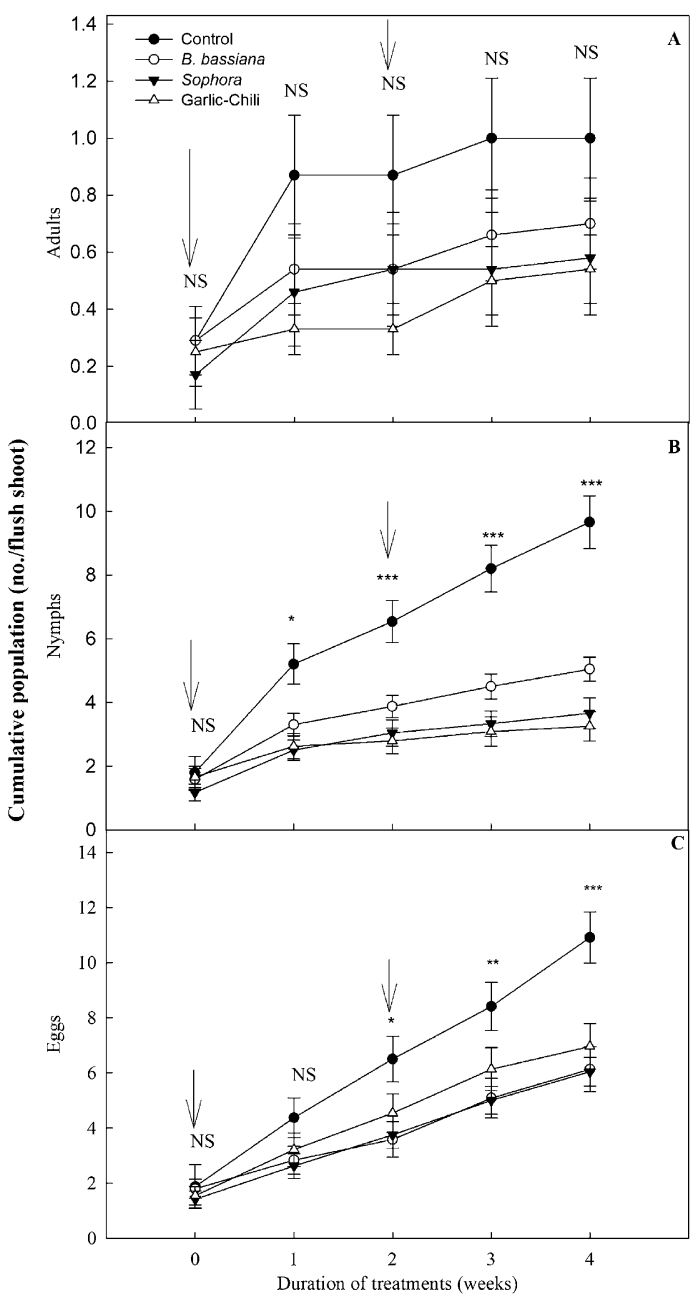

Fig. 6. Cumulative average of ACP adults (A), nymphs (B), and eggs (C) per flush shoot in Tahiti lime trees treated with three commercial biopesticides (Sophora spp., garlic-chili pepper concentrated emulsion, or B. bassiana). Points represent the mean of four values \pm SE. ${ }^{\text {NS }}$ No significance; ***significant difference $(P \leq$ $0.001)$; **significant difference $(P \leq 0.01)$; *significant difference $(P \leq 0.05)$ compared with the control according to the Tukey test. Foliar treatment sprays were carried out at 0 weeks after treatments.

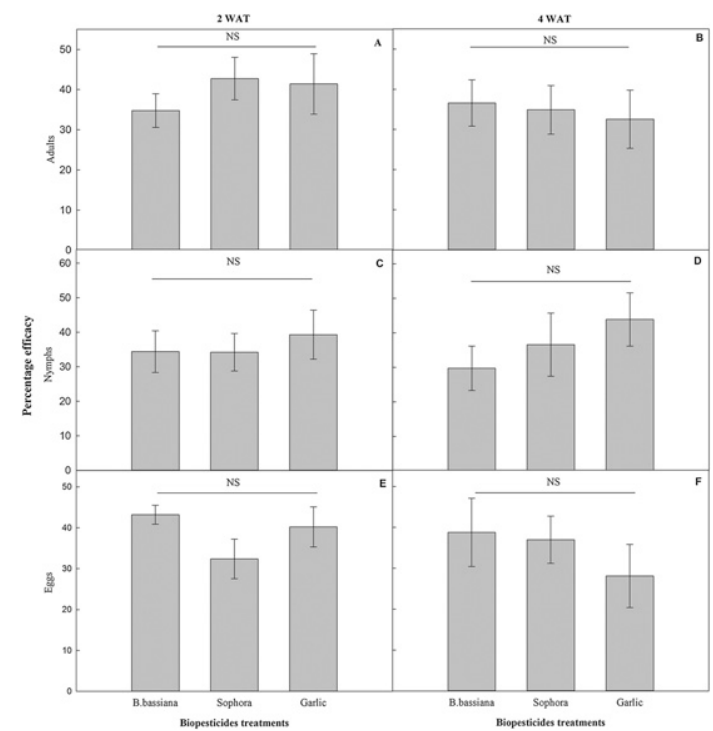

Fig. 7. Summary of the efficiency percentage per flush shoot in Tahiti lime trees treated with three commercial biopesticides (Sophora spp., garlic-chili pepper concentrated emulsion, or B. bassiana) at 2 [adults (A), nymphs $(\mathbf{C})$, and eggs (E)] and 4 [adults (B), nymphs (D), and eggs (F)] week after

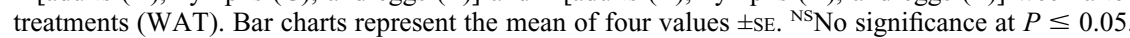
Foliar treatment sprays were carried out at 0 and 2 weeks after treatments.
Mann et al. (2011) and Cazares-Alonso et al. (2014) also indicated that garlic extracts show repellent activity and inhibition of ACP. Garlic extracts contain compounds such as trisulfites, which are known as insect-repellent chemicals (Mann et al., 2011). On the other hand, chili pepper contains capsaicin, which has lethal, antifeeding, and/or repellent effects on invertebrates (Baidoo and Mochiah, 2016; Kazem and El-Shereif, 2010). Regarding the use of the commercial extracts based on alkaloids, studies by Khan et al. (2013) and (2014) showed that the use of plant alkaloids such as tropane caused nymph mortality higher than $50 \%$ in laboratory and field conditions. Also, Zanardi et al. (2015) reported the positive effects on ACP control with the use of another plant alkaloid, matrine. These conclusions are in accordance with our findings in which Sophora (matrine) sprays caused a reduction of over $50 \%$ in ACP nymphs. A plausible explanation for ACP nymph reduction in our study could be that plant extract alkaloids affect the production of acetylcholine by the insect and cause an antifeeding effect since they are applied on the plant surface (Ali et al., 2017; Khan et al., 2013).

The development of sustainable strategies in commercial citrus orchards is of vital importance for ACP management and spread in Colombia. The application of commercial biopesticides based mainly on plant extracts or entomopathogenic fungi is a strategy that can be used to minimize the use of chemical synthesis insecticides within an IPM program, especially in tropical dry forest habitats, since these products reduced mainly ACP immatures (nymphs and eggs). Longterm studies are necessary to determine the potential use of $B$. bassiana and plant extracts in different habitats.

\section{Literature Cited}

Agronet. 2017. Red de información y comunicación del sector agropecuario. 5 May 2018. <http:// www.agronet.gov.co/Paginas/default.aspx $>$.

Ali, S., C. Zhang, Z. Wang, X.M. Wang, J.H. Wu, A.G.S. Cuthbertson, Z. Shao, and B.L. Qiu. 2017. Toxicological and biochemical basis of synergism between the entomopathogenic fungus Lecanicillium muscarium and the insecticide matrine against Bemisia tabaci (Gennadius). Sci. Rep. 7:46558.

Baidoo, P.K. and M.B. Mochiah. 2016. Comparing the effectiveness of garlic (Allium sativum L.) and hot pepper (Capsicum frutescens L.) in the management of the major pests of cabbage Brassica oleracea (L.). Sustain. Agr. Res. 5:83-91.

Boina, D.R. and J.R. Bloomquist. 2015. Chemical control of the Asian citrus psyllid and of Huanglongbing disease in citrus. Pest Mgt. Sci. 71:808-823.

Cazares-Alonso, N.P., M.J. Verde Star, J.I. López Arroyo, and I.H. Almeyda León. 2014. Evaluation of different plant extracts against the Asian citrus psyllid Diaphorina citri (Hemiptera: Liviidae). Rev. Colomb. Entomol. 40:67-73.

Chen, X.D. and L.L. Stelinski. 2017. Resistance management for Asian citrus psyllid, Diaphorina citri Kuwayama, in Florida. Insects 8:103. 
Ebratt-Ravelo, E.E., L.T. Rubio-González, V.A. Costa, A.P. Castro-Ávila, E.M. ZambranoGómez, and J.E. Ángel-Díaz. 2011. Diaphorina citri (Kuwayama, 1907) and Tamarixia radiata (Waterson, 1922) in citrus crops of Cundinamarca, Colombia. Agron. Colomb. 29:487-493.

Fang, X.D., G.C. Ouyang, H.L. Lu, M.F. Guo, and W.N. Wu. 2018. Ecological control of citrus pest primarily using predatory mites and the biorational pesticide matrine. Intl. J. Pest Mgt. 64(3):1-9.

Ferreira Pinto, A.P., A. Batista Filho, J.E.M. Almeida, and I.M. Wenzel. 2012. Beauveria bassiana pathogenicity to Diaphorina citri and compatibility of the fungus with phytosanitary products. Pesqui. Agropecu. Bras. 47:16731680.

Gandarilla-Pacheco, F.L., J.I. López-Arroyo, L.J. Galán-Wong, and I. Quintero-Zapata. 2013. Pathogenicity of native entomopathogenic fungi from the Mexican citrus-growing area against Diaphorina citri Kuwayama (Hemiptera: Liviidae). Southwest. Entomol. 38(2): 325-338.

Halbert, S.E., X. Sun, and W.N. Dixon. 2000. Asian citrus psyllid and citrus greening disease. Citrus Ind. 91:22-24.

Henderson, C.F. and E.W. Tilton. 1955. Tests with acaricides against the brown wheat mite. J. Econ. Entomol. 48:157-161.

Huang, J.L., M. Lv, and H. Xu. 2017. Semisynthesis of some matrine ether derivatives as insecticidal agents. RSC Advances 7:15997-16004.

Ibarra-Cortés, K.H., A.W. Guzmán-Franco, H. González-Hernández, L.D. Ortega-Arenas, J.A. Villanueva-Jimenez, and A. Robles-Bermudez. 2017. Susceptibility of Diaphorina citri (Hemiptera: Liviidae) and its parasitoid Tamarixia radiata (Hymenoptera: Eulophidae) to entomopathogenic fungi under laboratory conditions. Neotrop. Entomol. doi: 10.1007/s13744-0170539-6.

ICA. 2015. Resolución 2390 de 2015: "Por medio de la cual se declara el estado de emergencia fitosanitaria en el territorio nacional por la presencia de adultos de Diaphorina citri infectados con la bacteria de la enfermedad del HLB de los cítricos". 5 May 2018. <http://www.ica. gov.co/Normatividad/>.

Kazem, M.G.T. and S.A.E.H.N. El-Shereif. 2010. Toxic effect of capsicum and garlic xylene extracts in toxicity of boiled linseed oil formulations against some piercing sucking cotton pests. American-Eurasian J. Agr. Environ. Sci. 8:390-396.
Khan, A. A., M. Afzal, A.M. Raza, A.M. Khan, J. Iqbal, H.M. Tahir, J.A. Qureshi, A. Khaliq, M. Zia-ul-Haq, and M.A. Aqeel. 2013. Toxicity of botanicals and selective insecticides to Asian citrus psylla, Diaphorina citri K. (Homoptera: Psyllidae) in laboratory conditions. Jökull Journal 63:52-72.

Khan, A.A., M. Afzal, J.A. Qureshi, A.M. Khan, and A.M. Raza. 2014. Botanicals, selective insecticides, and predators to control Diaphorina citri (Hemiptera: Liviidae) in citrus orchards. Insect Sci. 21:717-726.

Khan, A.A., M. Afzal, M.I. Ullah, A.M. Khan, and S. Saeed. 2015. Asian citrus psyllids (Hemiptera: Psyllidae), its vectored disease "Huanglongbing" and its eco-friendly management. Appl. Sci. Bus. Econ. 2(3):1-12.

Kumar, V., P.B. Avery, J. Ahmed, R.D. Cave, C.L. McKenzie, and L.S. Osborne. 2017. Compatibility and efficacy of Isaria fumosorosea with horticultural oils for mitigation of the Asian citrus psyllid, Diaphorina citri (Hemiptera: Liviidae). Insects 8(4):119.

Lezama-Gutiérrez, R., J., Molina-Ochoa, O. Chávez-Flores, C.A. Ángel-Sahagún, S.R. Skoda, G. Reyes-Martínez, M. Barba-Reynoso, O. Rebolledo-Domıínguez, G.M.L. Ruíz-Aguila, and J.E. Foster. 2012. Use of the entomopathogenic fungi Metarhizium anisopliae, Cordyceps bassiana and Isaria fumosorosea to control Diaphorina citri (Hemiptera:Psyllidae) in Persian lime under field conditions. Intl. J. Trop. Insect Sci. 32(1):39-44.

Mann, R.S., R.L. Rouseff, J.M. Smoot, W.S Castle, and L.L. Stelinski. 2011. Sulfur volatiles from Allium spp. affect Asian citrus psyllid, Diaphorina citri Kuwayama (Hemiptera: Psyllidae), response to citrus volatiles. Bull. Entomol. Res. 101:89-97.

Mao, L. and G. Henderson. 2007. Antifeedant activity and acute and residual toxicity of alkaloids from Sophora flavescens (Leguminosae) against formosan subterranean termites (Isoptera: Rhinotermitidae). J. Econ. Entomol. 100:866-870.

Mejía-Vásquez, L.M. 2016. Evaluacionìn de eficacia bioloìgica de plaguicidas sobre Diaphorina citri Kuwayama (Hemiptera: Liviidae). Universidad Nacional de Colombia, Sede Medellin. Magister Diss.

Oliveira, D.G.P., G. Pauli, G.M. Mascarin, and I. Delalibera. 2015. A protocol for determination of conidial viability of the fungal entomopathogens Beauveria bassiana and Metarhizium anisopliae from commercial products. J. Microbiol. Methods 119:44-52.
Orduño-Cruz, N., A.W. Guzmán-Franco, E. Rodríguez-Leyva, R. Alatorre-Rosas, H. GonzálezHernández, and G. Mora-Aguilera. 2015. In vivo selection of entomopathogenic fungal isolates for control of Diaphorina citri (Hemiptera: Liviidae). Biol. Control 90:1-5.

Padulla, L.F.L. and S.B. Alves. 2009. Suscetibilidade de ninfas de Diaphorina citri a fungos entomopatogênicos. Arq. Inst. Biol. (Sao Paulo) 76:297-302.

Saldarriaga-Ausique, J.J., C.P. D’Alessandro, M.R. Conceschi, G.M. Mascarin, and D.L. Junior. 2017. Efficacy of entomopathogenic fungi against adult Diaphorina citri from laboratory to field applications. J. Pest Sci. 90:947-960.

Santivañez, T., G. Mora Aguilera, G. Diaz Pinilla, J.I. Lopez Arrollo, and P. Vernal Hurtado. 2013. Citrus: Marco estratégico para la gestión regional del Huanglongbing en América Latina y el Caribe. FAO, Santiago de Chile, Chile.

Santos, M.S., O.Z. Zanardi, K.S. Pauli, M.R. Forim, P.T. Yamamoto, and J.D. Vendramim. 2015. Toxicity of an azadirachtin-based biopesticide on Diaphorina citri Kuwayama (Hemiptera: Liviidae) and its ectoparasitoid Tamarixia radiata (Waterston) (Hymenoptera: Eulophidae). Crop Prot. 74:116-123.

Sétamou, M., D. Flores, J.V. French, and D.G. Hall. 2008. Dispersion patterns and sampling plans for Diaphorina citri (Hemiptera: Psyllidae) in citrus. J. Econ. Entomol. 101:1478-1487.

Tiwari, S., R.S. Mann, M.E. Rogers, and L.L. Stelinski. 2011. Insecticide resistance in field populations of Asian citrus psyllid in Florida. Pest Mgt. Sci. 67:1258-1268.

Weathersbee, A.A., III, and C.L. McKenzie. 2005. Effect of a neem biopesticide on repellency, mortality, oviposition, and development of Diaphorina citri (Homoptera: Psyllidae). Fla. Entomol. 88:401-407.

Xin, X., Y. Man, F. Leilei, M. Zhi-Qing, and Z. Xing. 2016. The botanical pesticide derived from Sophora flavescens for controlling insect pests can also improve growth and development of tomato plants. Ind. Crops Prod. 92:13-18.

Zanardi, O.Z., L. do Prado Ribeiro, T.F. Ansante, M.S. Santos, G.P. Bordini, P.T. Yamamoto, and J.D. Vendramin. 2015. Bioactivity of a matrine-based biopesticide against four pest species of agricultural importance. Crop Prot. 67:160-167.

Zehnder, G., G.M. Gurr, S. Kuhne, M.R. Wade, S.D. Wratten, and E. Wyss. 2007. Arthropod pest management in organic crops. Annu. Rev. Entomol. 52:57-80. 